\title{
UMA VISÃO SOBRE A GESTÃO DO ESGOTAMENTO SANITÁRIO NO BRASIL
}

\author{
OVERVIEW ON THE MANAGEMENT OF SEWERAGE SYSTEM IN BRAZIL
}

\author{
Luciane Dusi Pereira ${ }^{1}$ \\ Alexandre Bach Trevisan² \\ Fabrício Jacques Vieira ${ }^{3}$ \\ Catiane Pelissari ${ }^{4}$ \\ Pablo Heleno Sezerino ${ }^{5}$
}

Recebido em: 30 jul. 2020

Aceito em: 26 out. 2020

\section{RESUMO}

A gestão pública relacionada às ações de saneamento básico, em específico sobre a dimensão do esgotamento sanitário, foi o tema deste artigo. O conceito de governança pública foi apresentado juntamente com uma visão geral sobre os instrumentos e os atores nos três níveis: municipal, estadual e federal. Tratou-se também de construir uma breve linha do tempo sobre os serviços de esgotamento sanitário no Brasil. O papel dos municípios na gestão do esgotamento foi abordado através de um aprofundamento sobre a política e o plano de saneamento municipais. Foram abordados os tipos de organizações que prestam o serviço no Brasil, bem como o atendimento dos serviços, considerando os modais de esgotamento com rede e tratamento centralizado, e por solução individual. Os fundamentos teóricos da constituição das tarifas e o papel das agências

\footnotetext{
${ }^{1}$ Luciane Dusi Pereira, Mestre em Engenharia Ambiental, Universidade do Vale do Rio do Peixe UNIARP, Doutoranda no PPGEA da Universidade Federal de Santa Catarina - UFSC. E-mail: dusi@uniarp.edu.br.

${ }^{2}$ Alexandre Bach Trevisan, Mestre em Engenharia Química, Universidade Federal de Santa Catarina - UFSC, Doutorando no PPGEA da UFSC. E-mail: alexbachtrevisan@gmail.com.

3 Fabrício Jacques Vieira, Engenheiro Sanitarista e Ambiental, Universidade Federal de Santa Catarina - UFSC, Mestrando no PPGEA da UFSC E-mail: fabriciojv@yahoo.com.br.

${ }^{4}$ Catiane Pelissari, Doutora em Engenharia Ambiental, Universidade Federal de Santa Catarina UFSC, Pesquisadora no Grupo de Estudos em Saneamento Descentralizado - GESAD/UFSC. E-mail: catianebti@gmail.com.

5 Pablo Heleno Sezerino, Doutor em Engenharia Ambiental, Supervisor do Grupo de Estudos em Saneamento Descentralizado - GESAD, Universidade Federal de Santa Catarina - UFSC. E-mail: pablo.sezerino@ufsc.br.
} 
reguladoras também foram abordados, no sentido de abranger o tema da forma mais ampla possível e trazendo os aspectos relevantes para uma visão geral. Com a finalidade de ilustrar a abordagem com informações estatísticas sobre o tema, foram utilizados os bancos de dados do Instituto Brasileiro de Geografia e Estatística; do Sistema Nacional de Informações sobre Saneamento; e do estudo da Agência Nacional de Águas, juntamente com a Secretaria Nacional de Saneamento denominado Atlas Esgoto. Tratou-se de elaborar representações gráficas variadas, com a intensão de simplificar a leitura e promover o entendimento multidisciplinar sobre atuação dos atores, corroborando com a necessidade do envolvimento da sociedade.

PALAVRAS-CHAVES: Esgotamento sanitário, governança, gestão, política nacional de saneamento básico.

\section{ABSTRACT}

Public management related to basic sanitation actions, specifically on the dimension of sanitation, was the theme of this article. The concept of public governance was presented together with an overview of the instruments and actors at the three levels: municipal, state and federal. Also a brief timeline on sewage services in Brazil was produced. The role of municipalities in the management of sewage was addressed through an in-depth look at municipal sanitation policy and plan. The types of organizations that provide the service in Brazil were addressed, as well as the service provided, considering different models of sewerage conceptions such as network and centralized treatment as well as by individual solution. The theoretical foundations of setting tariffs and the role of regulatory agencies were also addressed, in order to cover the topic as broadly as possible and bringing the relevant aspects to an overview. In order to illustrate the approach with statistical information on the topic, the databases of the Brazilian Institute of Geography and Statistics were used; the National Sanitation Information System; and the study of the National Water Agency together with the National Sanitation Secretariat called Atlas Sewer. Finally, it was a question of elaborating varied graphic representations, with the intention of simplifying the reading and promoting the multidisciplinary understanding of the actors' performance, corroborating the need for the involvement of society.

KEYWORDS: Sanitation, governance, management, national sanitary policy.

\section{INTRODUÇÃO}

A implantação de um sistema de gestão e governança eficientes para o Ignis / Caçador | v.9 | n.1 | jan./jun. 2020 
esgotamento sanitário no Brasil é um desafio a ser superado, de forma a permitir que todos tenham acesso aos serviços, e que estes se sustentem economicamente.

A forma de gerir os serviços no território brasileiro variou ao longo dos anos. O que em época remota tratava-se de manter bons níveis de higiene entre a população, se transformou em serviços de infraestrutura promovendo, na maioria dos casos, o afastamento do esgoto da fonte geradora até uma rede de drenagem, córrego ou rio, aumentando a poluição dos recursos hídricos. Já nas áreas carentes o problema se agrava, pois estes estágios não foram vivenciados e o esgoto tende em muitos casos a correr a céu aberto ou ser direcionada para infiltração direta no solo. Em face disto, a legislação brasileira tratou de diferenciar a abordagem nestes espaços, prevendo subsídios e prioridades de atendimento. Também é importante destacar que a literatura brasileira avançou na discussão sobre a temática da gestão e da governança do saneamento nas últimas décadas, notadamente a partir da Lei 11.445/2007 e, mais recentemente, pela Lei № 14.026, de 15 de julho de 2020.

Neste estudo a proposta foi trabalhar o tema da gestão do esgotamento sanitário no Brasil, mediante um enfoque na Lei 11.445/2007 e trazendo informações atuais com base em pesquisas realizadas nos principais bancos de dados do setor. Desta forma, foram identificadas as instituiç̧̃̃es envolvidas, o papel dos municípios, os instrumentos de gestão criados pela legislação, os modelos (centralizado e descentralizado) de esgotamento adotados no país, os princípios norteadores da formulação das tarifas cobradas pelo serviço e o papel da regulação. Um panorama das questões apresentadas e discutidas neste artigo é apresentado na figura 1. 
Figura 1: Componentes da gestão e governança do esgotamento sanitário no Brasil.

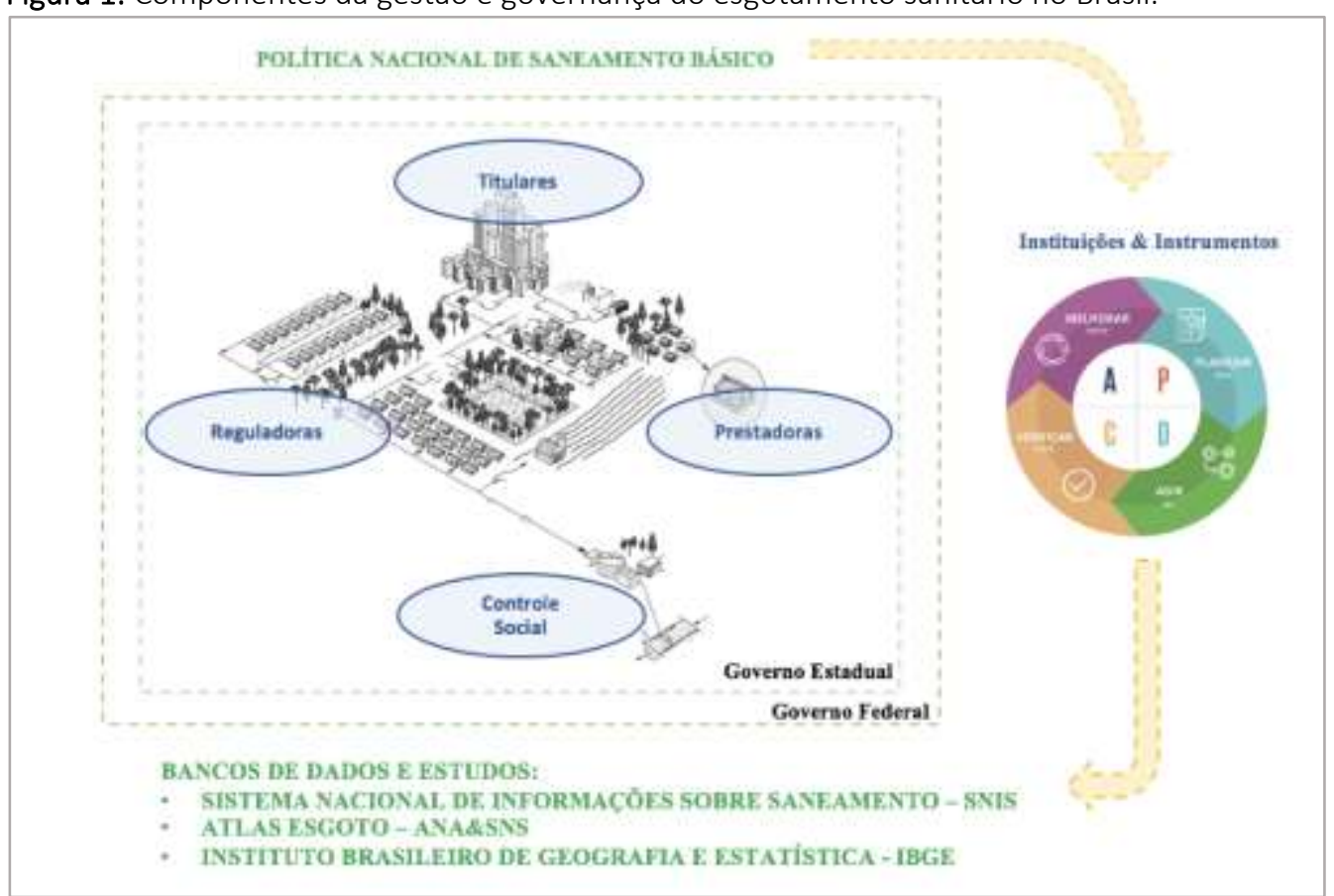

Fonte: Os próprios autores.

\section{DESENVOLVIMENTO}

\section{GOVERNANÇA DO SANEAMENTO NO BRASIL}

A governança pública, segundo o Decreto Federal 9.203/2017, é entendida como o conjunto de mecanismos de liderança, estratégia e controle postos em prática para avaliar, direcionar e monitorar a gestão, com vistas à condução de políticas públicas e à prestação de serviços de interesse da sociedade (BRASIL, 2017). Tendo em vista este enfoque, é possível fazer uma leitura da Política Nacional de Saneamento Básico (PNSB) por meio da Lei Federal 11.445 de janeiro de 2007 e destacar os principais elementos que dão suporte à governança do saneamento no Brasil, quais sejam: as instituições envolvidas com a gestão dos serviços; os instrumentos de controle, monitoramento e operação disponíveis; os princípios; as responsabilidades e os direitos dos envolvidos. Na Figura 2 representa-se o conceito de governança pública aplicada à dimensão do esgotamento sanitário, enfatizando os princípios, as diretrizes e o alcance de 
resultados junto às políticas públicas e à prestação dos serviços

Figura 2: Representação do conceito de governança pública aplicada ao esgotamento sanitário.

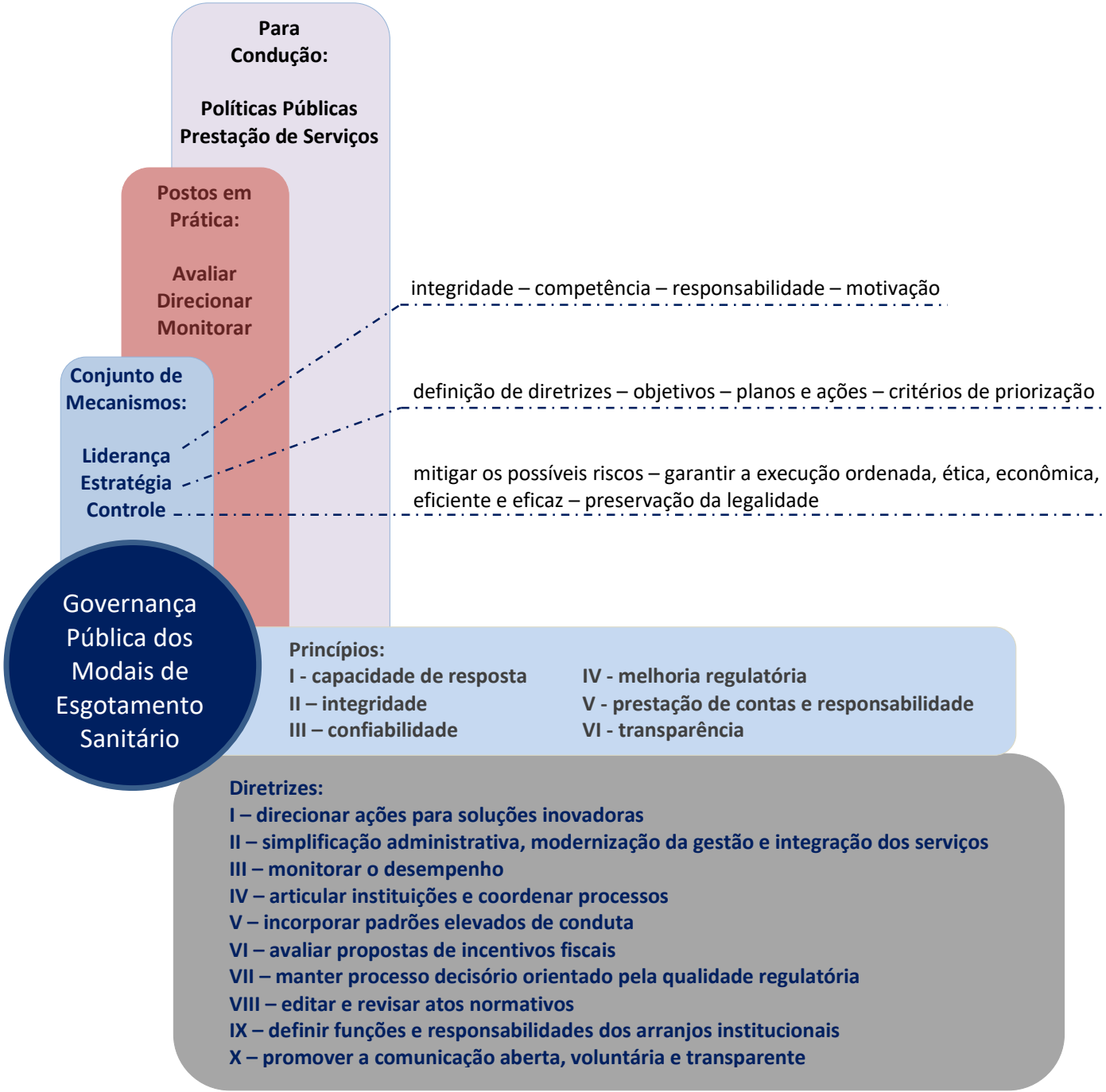

Fonte: Adaptado do DECRETO № 9.203, DE 22 DE NOVEMBRO DE 2017.

Isto posto, identifica-se os municípios como sendo os titulares responsáveis pelo serviço de esgotamento sanitário no Brasil, podendo delegar a organização, a regulação, a fiscalização e a prestação desse serviço (BRASIL, 2007). Todavia, ao poder municipal cabe, de forma indelegável, a elaboração da Política Municipal de Saneamento Básico (PMSB) e do Plano Municipal de Saneamento Básico (PLMSB), bem como, o acompanhamento de todo o processo de governança 
relacionado à prestação do serviço. Já a participação da sociedade é assegurada em todas as esferas.

Na esfera estadual, o marco regulatório de 2007 previu que os estados atuarão dando suporte aos municípios por meio da constituição dos Fundos Estaduais de Saneamento e dos Conselhos Estaduais de Saneamento, bem como participando do planejamento regional junto ao governo federal. Cabe salientar que os estados tiveram uma participação local maior entre os anos de 1971 a 1986, durante o Programa Nacional de Saneamento - PLANASA, época em que foram criadas as Companhias Estaduais de Saneamento Básico (CESB), porém, em geral, estas transformaram-se em operadoras de serviços de abastecimento de água ao invés do efetivo saneamento básico (BASTOS, 2009).

Já na esfera federal, o governo atua por meio do estabelecimento da Política Nacional de Saneamento Básico (PNSB) e do Plano Nacional de Saneamento Básico (PLANSAB), documentos que estabelecem diretrizes gerais à gestão das quatro dimensões do saneamento, bem como com o aporte financeiro através do repasse dos recursos federais e por meio da Fundação Nacional de Saúde - Funasa. Na Figura 3 é possível verificar a interação entre as instituições e instrumentos da gestão do saneamento.

Figura 3: Instituições e instrumentos de gestão do saneamento no Brasil (Lei 11.445/2007).

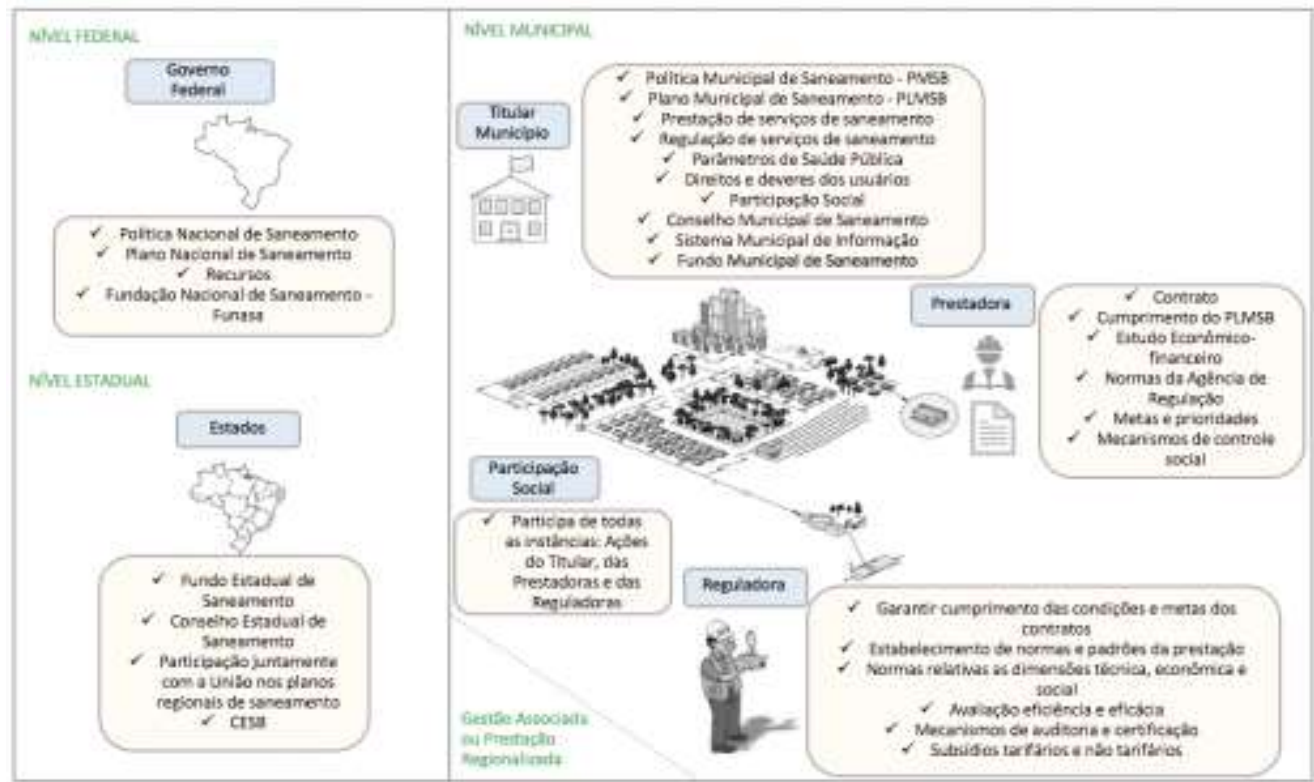

Fonte: Elaborado com base na Lei 11.445/2007 (BRASIL, 2007) e (GIKAS; TCHOBANOGLOUS, 2008). 
Dentro da hierarquia da estrutura de gestão, o principal instrumento que irá definir o modis operandi dos serviços de saneamento no nível local é a Política Municipal de Saneamento (PMSB), que vai variar nos seus principais requisitos de acordo com a visão local. Segundo Moraes (2009) a compreensão sobre o conteúdo desta lei passa pelo entendimento dos fatores políticos, sociais, econômicos e outros, que determinam a atuação do governo local em cada contexto histórico. Neste sentido, para compreender a situação atual, torna-se parte importante resgatar um pouco da história da atuação das diferentes esferas do governo brasileiro na implantação e gestão destes serviços. Na figura 4 evidencia-se uma linha do tempo que ilustra esta trajetória, apontando suas principais épocas.

Vê-se, portanto, que é relativamente recente a definição do papel do município na gestão do saneamento. Até o ano de 1960, as políticas estavam centralizadas no nível federal. Já no período do PLANASA os estados assumiram os serviços, e a partir da década de 1990 os municípios iniciam o processo de municipalização da gestão, ganhando apoio com a Lei 11.445 em 2007. Atualmente é clara a titularidade dos municípios na implementação dos serviços de saneamento no nível local, sendo facultada a gestão associada dos serviços, que trata da associação voluntária entre os municípios por convênio de cooperação ou consórcio público (BRASIL, 2007). Com a recém aprovação do novo marco regulatório, Lei 14.026 de 15 de julho de 2020, é preciso analisar as novidades trazidas para o setor.

Figura 4: Linha do tempo da trajetória do Saneamento no Brasil.

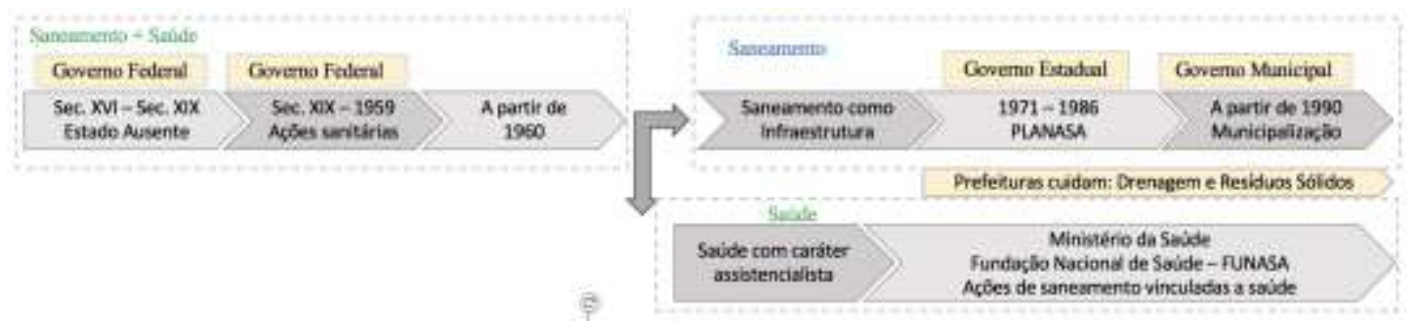

Fonte: Elaborado com base em Moraes (2009).

Neste processo histórico, também foi se alterando a visão sobre o fornecimento destes serviços, passando de uma visão assistencialista para de mercado, com uma certa tendência de privatização, porém ainda incipiente no Brasil, contudo destacado no novo marco legal, essa realidade poderá modificar-se 
nos próximos anos.

Outro elemento que fica evidente nesta linha do tempo, é o fato do serviço de saneamento ter se originado com a gestão da saúde pública, onde a separação ocorreu somente na década de 1960, a partir de quando o saneamento foi visto mais como uma medida de infraestrutura. Todavia, a atuação do Sistema Único de Saúde (SUS) ainda é presente na gestão do saneamento, principalmente nos pequenos municípios, através da Fundação Nacional de Saúde - Funasa e as vigilâncias sanitárias municipais e estaduais.

\section{O PAPEL DOS MUNICÍPIOS NA GESTÃO DO ESGOTAMENTO SANITÁRIO}

Os principais instrumentos da gestão e do esgotamento sanitário no nível municipal, visando garantir a gestão e a governança dos serviços, são: a PMSB, o PLMSB, o contrato com as Prestadoras (opcional) e o contrato com as Agências Reguladoras (opcional). Na experiência brasileira, o conteúdo da PMSB é bastante variado, por vezes incompleto ou diluído em mais de uma lei. Pensando nisto, algumas instituições de apoio e fomento trataram de elaborar e fornecer aos municípios alguns modelos, como foi o caso da Fundação Nacional de Saúde Funasa e de alguns Ministérios Públicos Estaduais.

Na figura 5 estão apresentados os principais instrumentos de gestão local e pode-se observar uma indicação de conteúdo para a PMSB baseada na Lei 11.445/2007: o estabelecimento do PLMSB; a indicação sobre a delegação da prestação do serviço e da regulação; a definição de um sistema de informações sobre saneamento; o estabelecimento de mecanismos de participação social e de direitos e deveres dos usuários; a criação de um Conselho e de um Fundo Municipal de Saneamento.

O PLMSB, como o próprio nome já diz, refere-se a fase "Plan" do PDCA, onde o aspecto mais relevante está relacionado ao estabelecimento das metas de curto, médio e longo prazos para a universalização dos serviços de saneamento. Pode-se observar na figura 5 uma itemização do conteúdo deste instrumento com os seguintes elementos: um diagnóstico de toda a área do município (rural e urbana) abordando a situação atual e os impactos relacionados às quatro dimensões do saneamento (água, esgoto, resíduos sólidos e drenagem urbana); estabelecimento de objetivos e metas; programas e projetos que visem o 
cumprimento das metas estabelecidas; ações para emergências e contingências; e mecanismos de avaliações sistemáticas.

Figura 5: Principais instrumentos de gestão municipal do esgotamento sanitário.

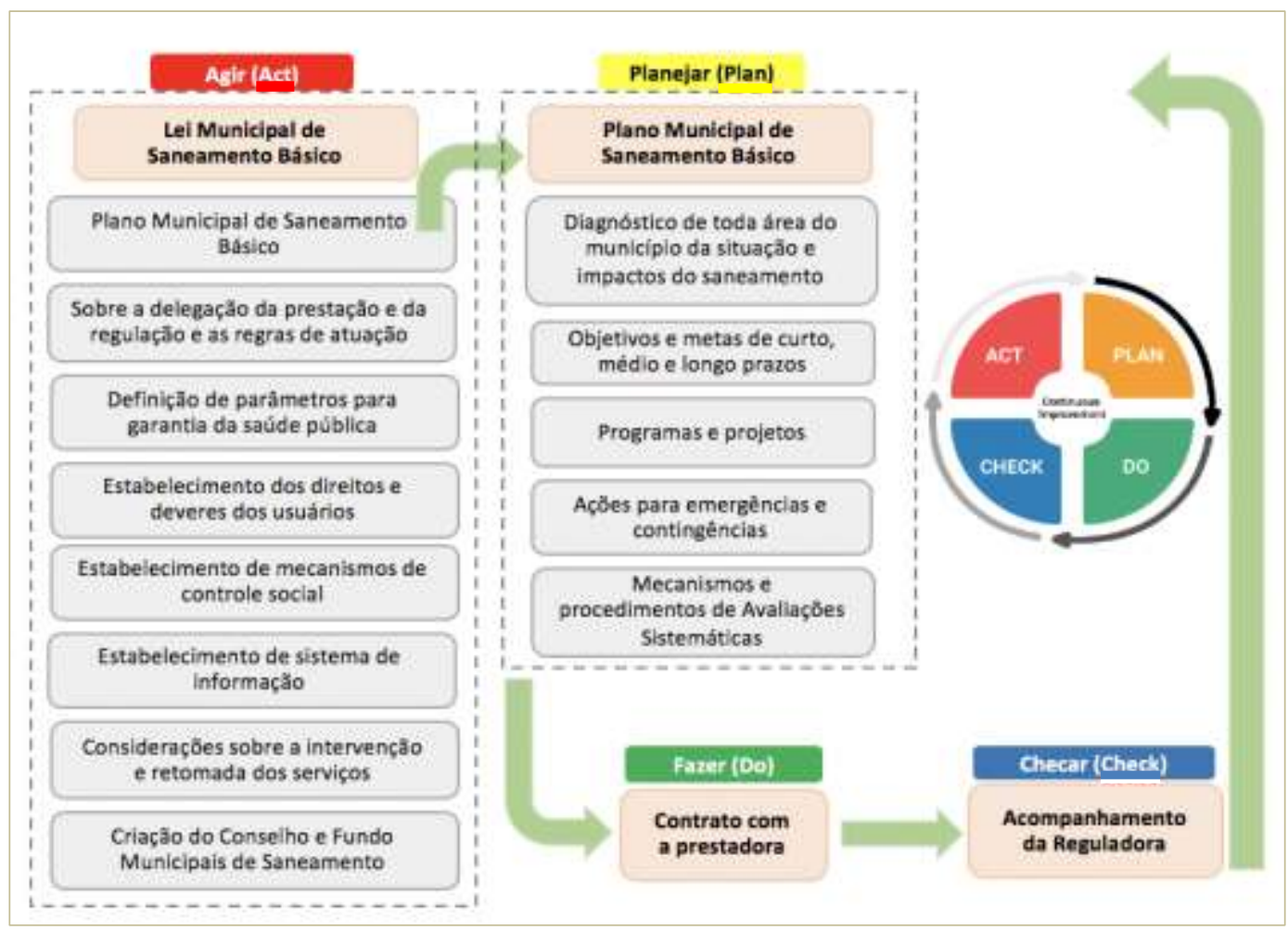

Fonte: Elaborado com base na Lei 11.445 (BRASIL, 2007) e na NBR ISO 14.001 (ABNT, 2015).

A busca dos municípios brasileiros para estruturarem-se com os instrumentos de gestão previstos em lei pode ser inferida observando os dados da pesquisa realizada pelo IBGE6 em 2017, apresentados na Figura 6.

Os três estados da região sul do país são aqueles que possuem maior incidência da PMSB no Brasil: Santa Catarina com 87\% dos municípios, seguido do Rio Grande do Sul com 59\% e Paraná com 53\%. Já os estados com menor incidência das políticas municipais são Alagoas com 12\%, Pernambuco com 16\% e empatados com $17 \%$ estão os estados da Paraíba, Bahia e Maranhão, todos na região nordeste. A região Sul se destaca também com a maior incidência dos PLMSB, onde o estado de Santa Catarina apresenta $82 \%$ dos seus municípios com seus respectivos planos,

6 Os dados do IBGE se referem aos serviços de saneamento de forma global, contemplando as quatro dimensões: Água, Esgoto, Resíduos Sólidos e Drenagem. 
e os mesmos estados da região Nordeste (Alagoas, Pernambuco, Paraíba, Bahia e Maranhão) aparecem com a menor incidência destes planos (BRASIL-IBGE, 2017).

Figura 6: Implantação dos Instrumentos da Política Nacional de Saneamento no Brasil.

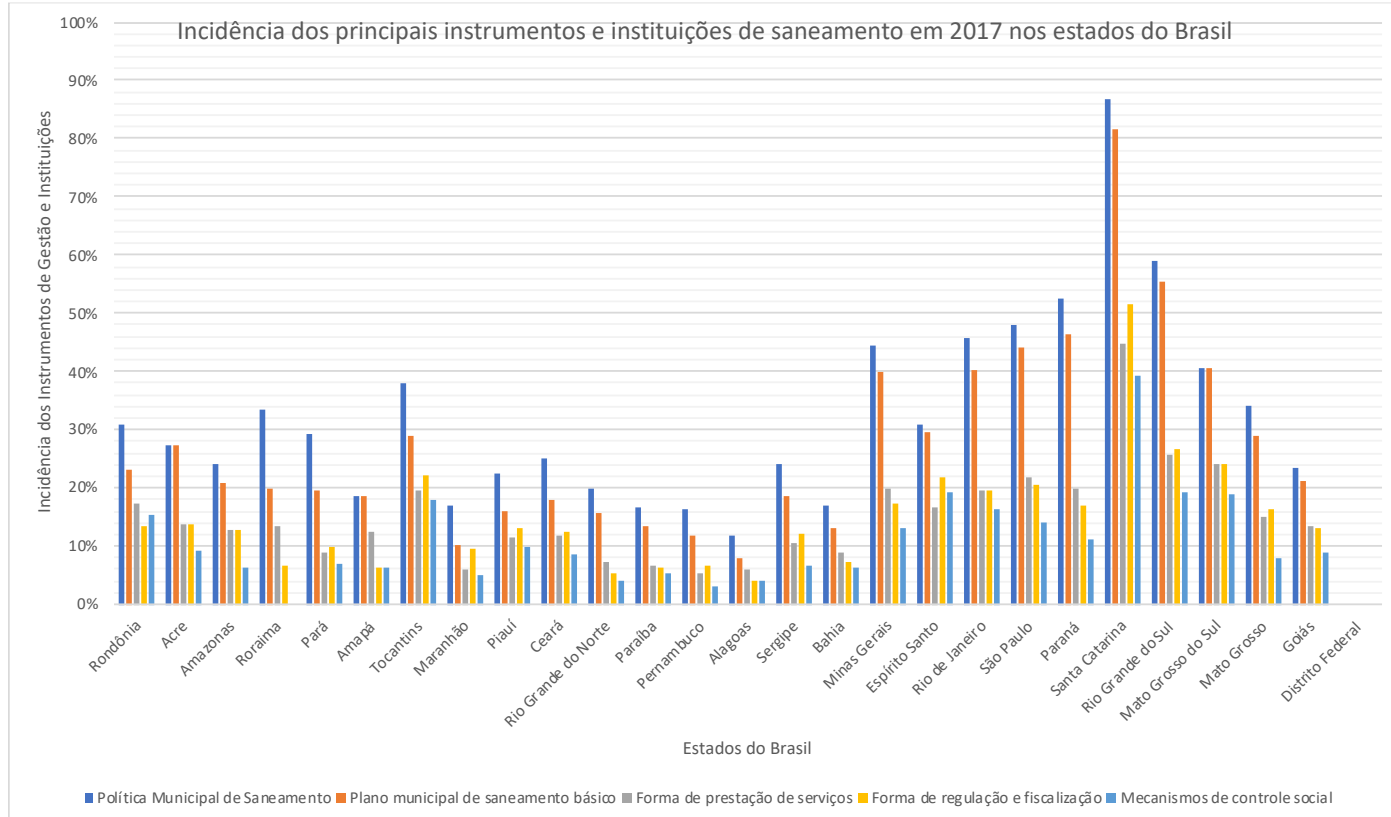

Fonte: Elaborado com base em (BRASIL-IBGE, 2017)

Pode-se observar que as porcentagens de incidência diminuem quando se trata da regulamentação sobre a forma de prestação dos serviços e de regulação, e em menor número pode-se visualizar a incidência dos mecanismos de controle social. Desta forma, vê-se que o Brasil passa por um processo de implantação local dos instrumentos.

Em relação a prestação dos serviços de esgotamento sanitário, correlato à fase "Do" do ciclo PDCA, estes podem ser executados pela própria municipalidade ou serem delegados, conforme mostrado na Figura 7. A modalidade de contrato de programa foi atingida por regras mais restritas no novo marco legal, questão a ser analisada futuramente. A estas prestadoras cabe implementar diversas ações tais como: projetos, obras, operação e monitoramento de sistemas; cobrança pelo uso, aplicação de subsídios, investimentos, buscar financiamentos; gerar informações aos diferentes atores, prestação de contas, entre outras atividades. 
Figura 7: Formas de prestação dos serviços de esgotamento sanitário.

\begin{tabular}{|c|c|c|c|}
\hline Titular & \multicolumn{2}{|c|}{ Forma de prestação } & Prestadora \\
\hline \multirow{4}{*}{$\begin{array}{l}\text { Município ou } \\
\text { Associação de Municípios. }\end{array}$} & Diretamente & \multicolumn{2}{|c|}{$\begin{array}{l}\text { Órgăo da administraçăo direta, facultado que contrate } \\
\text { terceiros (Lei 8.666), para determinadas atividades. }\end{array}$} \\
\hline & \multirow{3}{*}{ Por contrato } & $\begin{array}{l}\text { Mediant } \\
\text { licitação }\end{array}$ & $\begin{array}{l}\text { ermissão sempre precedida de } \\
\text { oncorréncia pública (Lei } 8.987 \text { ). }\end{array}$ \\
\hline & & $\begin{array}{l}\text { No ăn } \\
\text { mediant } \\
\text { de con }\end{array}$ & $\begin{array}{l}\text { soclada de serviços públicos } \\
\text { grama autorizado por contrato } \\
\text { por convênio de cooperaşäo } \\
\text { erados (Lei } 11.107 \text { ). }\end{array}$ \\
\hline & & $\begin{array}{r}\text { Por L } \\
\text { organiza }\end{array}$ & $\begin{array}{l}\text { ante autorizaçåo a usuários } \\
\text { vas ou associaçōes (Lei 11.445). }\end{array}$ \\
\hline
\end{tabular}

Fonte: Elaborado com base na Lei 11.445 (BRASIL, 2007), Lei 8.666 (BRASIL, 1993), Lei 8.987 (BRASIL, 1995), Lei 11.107 (BRASIL, 2005).

Segundo os dados do Sistema Nacional de Informações de Saneamento SNIS, são cinco os tipos de Natureza Jurídica7 das prestadoras de saneamento no Brasil. Existem as que pertencem a Administração Pública Direta; aquelas relacionadas ao grupo da Administração Pública Indireta que se dividem entre Autarquias, Empresas Públicas e Sociedades de Economia Mista com Gestão Pública; e por último as Empresas Privadas (SNIS, 2017). Na tabela 1 apresenta-se a incidência das prestadoras no Brasil, de acordo com a personalidade jurídica constituída, no que se refere ao fornecimento do serviço de esgotamento sanitário.

Tabela 1: Tipo das organizações prestadoras dos serviços de esgotamento sanitário no Brasil.

\begin{tabular}{|c|c|c|c|c|c|c|}
\hline \multirow{2}{*}{ Tipo de Organização } & \multirow{2}{*}{$\begin{array}{c}\text { Número de } \\
\text { Organizações }\end{array}$} & \multicolumn{3}{|c|}{ Abrangência } & \multirow{2}{*}{$\begin{array}{l}\text { Número de } \\
\text { Municípios }\end{array}$} & \multirow{2}{*}{$\begin{array}{r}\text { População } \\
\text { Atendida }\end{array}$} \\
\hline & & Local & MicroRegional & Regional & & \\
\hline Soc. Eco. Mista Adm. Pública & 30 & 7 & & 23 & 1326 & 69.420 .085 \\
\hline Autarquia & 302 & 298 & 3 & 1 & 305 & 20.166 .563 \\
\hline Empresa Privada & 70 & 66 & 3 & 1 & 89 & 8.226 .967 \\
\hline Administração Pública Direta & 969 & 969 & & & 969 & 6.635 .786 \\
\hline Empresa Pública & 5 & 4 & & 1 & 52 & 798.641 \\
\hline
\end{tabular}

Fonte: SNIS (2017).

Primeiramente, pode-se observar que o percentual da população brasileira atendida com o serviço de esgotamento sanitário, por prestadora

${ }^{7}$ A Natureza Jurídica classifica e enquadra o tipo de organização contábil e a relação de uma pessoa jurídica com o sistema de fiscalização econômica. 
formalmente cadastrada no SNIS, é cerca de 50\% do total da população brasileira, tomando-se por base os dados da população brasileira no ano de 2017. As empresas do tipo Sociedades de Economia Mista e Administração Pública, em comparação com as demais modalidades, são as que atendem maior porcentagem de habitantes (66\%) e de municípios (48\%), sendo considerado neste grupo as Companhias Estaduais de Saneamento Básico - CESB. É importante constatar que as empresas da Administração Pública Direta e as Autarquias, de caráter essencialmente local, constituem uma solução amplamente utilizada, abrangendo aproximadamente $46 \%$ dos municípios relacionados no SNIS, deflagrando a municipalização dos serviços que vem ocorrendo nas últimas décadas no Brasil. Já as prestadoras privadas no país têm o perfil de atuação local e ainda possuem números modestos, atuando em cerca de $3 \%$ dos municípios e atingindo um percentual de aproximadamente $8 \%$ dos habitantes segundo dados do SNIS.

Para elaborar um panorama do percentual da população brasileira atendida pelo serviço de esgotamento sanitário, optou-se por trabalhar com os dados do estudo denominado Atlas Esgoto, realizado pela Secretaria Nacional de Saneamento (SNS) juntamente com a Agência Nacional de Águas (ANA) em 2013. Esta escolha foi feita em função de que os dados do SNIS, fornecidos pelas prestadoras por meio dos formulários completos, abarcam somente os serviços que utilizam as soluções providas de rede coletora. Os dados do Atlas Esgoto apresentam como soluções adequadas ao serviço de esgotamento o atendimento com rede e também com as individuais. Já a situação com rede e sem tratamento seria inadequada, assim como sem rede e se tratamento, sendo este o caso mais crítico. Os dados deste estudo estão compilados e apresentados na Figura 8.

Vê-se pela figura 8 que estados como São Paulo e Paraná possuem percentual de $65 \%$ e $64 \%$ de atendimento por soluções com rede. Ao somar com as soluções individuais, o percentual de atendimento por solução adequada aumenta para 69\% em São Paulo e 75\% no Paraná. Noutros estados, como Santa Catarina, por exemplo, o percentual de atendimento com rede é bem menor, 24\%, todavia somando-se a este percentual, o montante atendido por solução individual, tem-se um total de $71 \%$ de atendimento com solução adequada neste estado.

Continuando com Santa Catarina como exemplo, se a análise for feita por município, em alguns casos o uso de soluções individuais aparecerá ainda mais expressivo, devido principalmente a incidência dos pequenos municípios neste 
estado, onde $54 \%$ dos municípios catarinenses possuem população urbana abaixo de 5.000 habitantes. Nestes locais, as soluções com redes coletoras tornam-se alternativas menos utilizadas devido ao complexo arcabouço instrumental que demandam e os custos envolvidos. Adicionalmente, há que se considerar o grande percentual de população rural nestes municípios, que se caracteriza por estar instalada de forma dispersa no território.

Figura 8: Atendimento em esgotamento sanitário no Brasil.

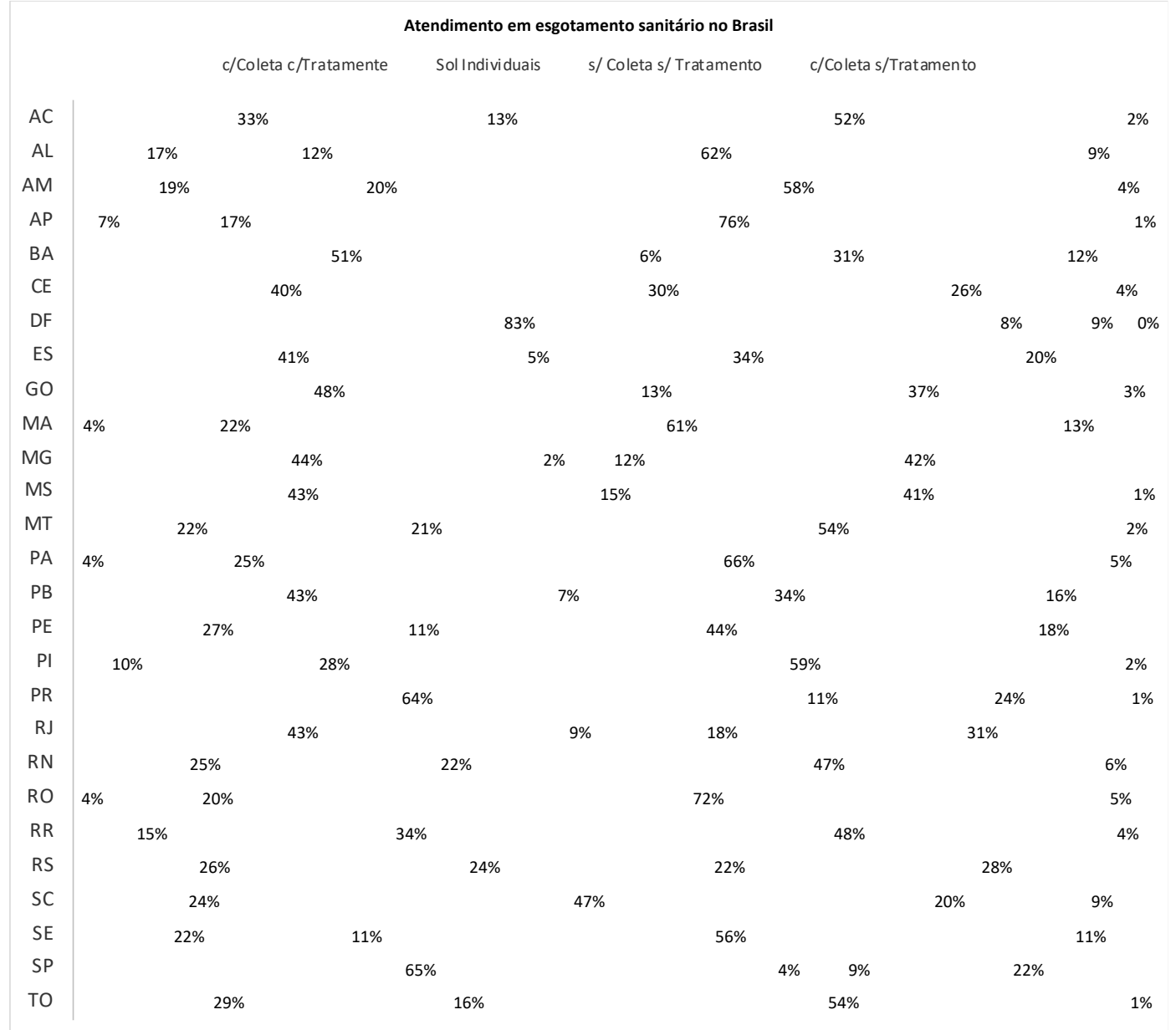

Fonte: Elaborado com base no Atlas Água e Esgoto (BRASIL- ATLAS, 2017).

MODELO DE ESGOTAMENTO SANITÁRIO E ASPECTOS FINANCEIROS

A escolha do arranjo tecnológico, bem como a opção pelo uso de sistema centralizado ou descentralizado de tratamento é um aspecto importante da gestão 
a ser equacionado. Esta escolha influencia nos custos operacionais, de manutenção e de monitoramento, bem como na forma de gestão destas atividades no que se refere às responsabilidades e prestação de contas.

Segundo o Decreto Federal 7.217/2010 (BRASIL, 2010), quando as soluções individuais são operadas por terceiros ou quando se atribua ao poder público a responsabilidade por sua operação, controle ou disciplina, estes sistemas podem ser considerados como serviços públicos, integrando-se à gestão municipal do saneamento como está sendo abordada neste artigo. No entanto, usualmente no Brasil estes sistemas não são geridos por meio dos instrumentos da Lei 11.445/2007, cabendo um aprimoramento neste sentido, por meio do estabelecimento de instrumentos de gestão municipal para este modal, além do instrumento estabelecido como "habite-se", que apresenta-se insuficiente para o acompanhamento da operação, manutenção e monitoramento da qualidade do sistema individual.

Cabe enfatizar ainda que, ao longo dos últimos dois séculos da história do desenvolvimento das cidades, construiu-se uma visão de que as alternativas mais eficientes para o esgotamento sanitário seriam os robustos sistemas de tratamento centralizados de esgoto. Entretanto, atualmente, considerando os desafios envolvidos com o uso sustentável dos recursos hídricos, esta perspectiva está sendo revista pela comunidade técnico-científica. Os planejadores agora estão sendo forçados a avaliar uma série de alternativas para o futuro das instalações de tratamento de esgoto, incluindo a utilização de instalações descentralizadas e do tipo satélite (GIKAS; TCHOBANOGLOUS, 2008).

Quanto ao aspecto financeiro, a prestação dos serviços públicos de esgotamento sanitário deve ter a sustentabilidade econômico-financeira assegurada, sempre que possível por meio de tarifas e outros preços públicos, cobrados como remuneração pelos serviços prestados. As tarifas devem ser fixadas de forma clara e objetiva, com publicidade antecedente aos reajustes e revisões (BRASIL, 2017).

Estes recursos tarifários virão das edificações permanentes urbanas, uma vez que devem se conectar às redes públicas de esgotamento sanitário sempre que estas estiverem disponíveis. Todavia, cabe ressaltar que, caso haja outro entendimento por parte da autoridade pública, pode haver disposições em contrário nas normas do Titular, da Entidade de Regulação e de Meio Ambiente que 
desobriguem a ligação (BRASIL, 2017). Na Figura 9 estão apresentados esquematicamente os fundamentos teóricos para a formulação das tarifas, tais como: as diretrizes, as orientações sobre o cálculo da cobrança e os subsídios tarifários e não tarifários.

Figura 9: Fundamentos teóricos para formulação das tarifas.

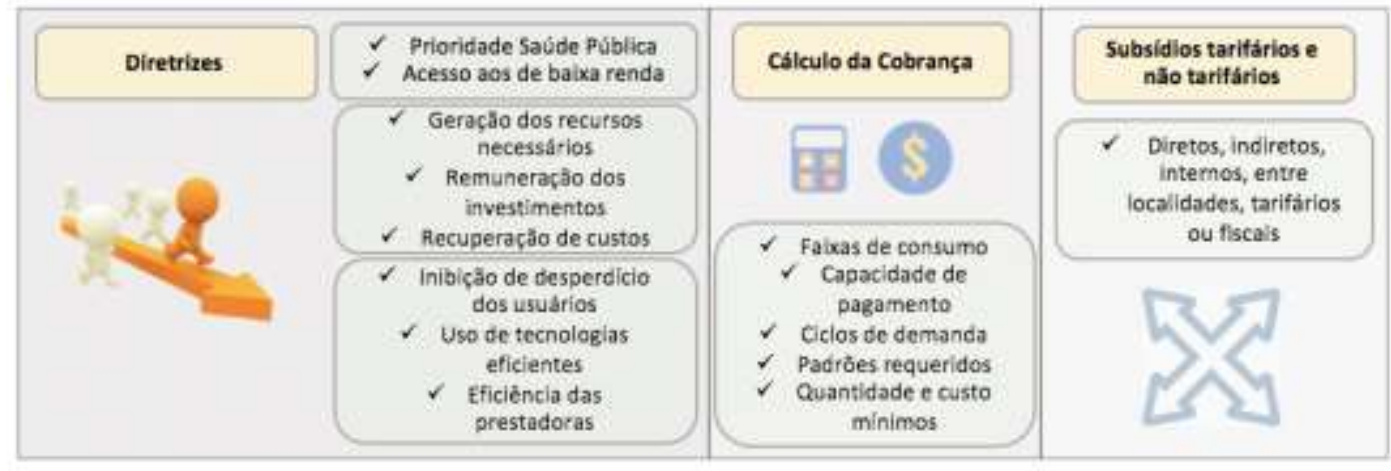

Fonte: Elaborado com base na Lei 11.445 (BRASIL, 2007) e Decreto 7.217 (BRASIL, 2010).

Dentro deste tema, é preciso considerar que as empresas de saneamento precisam não apenas ter receitas tarifárias que cubram seus custos e aumentem sua capacidade de investimento, mas precisam também buscar a obtenção de ganhos de produtividade para terem custos menores e serem mais eficientes e eficazes (ARAÚJO; BERTUSSI, 2018). Neste sentido, o desafio é grande, e estima-se que a necessidade de investimento em saneamento seja o dobro da necessidade dos investimentos no setor de energia elétrica, pois o setor é intensivo em uso de capital e possui elevados custos fixos (MADEIRA, 2010). O tratamento adequado do esgoto impõe altos custos e um exigente desempenho institucional, imputando severas condições aos pequenos municípios, devido a suas poucas possibilidades financeiras e fraquezas institucionais (HOPHMAYER-TOKICH, 2006).

Um estudo realizado pela Associação Brasileira de Agências Reguladoras ABAR avaliou as tarifas de esgotamento sanitário nos municípios brasileiros. Em virtude da falta de segregação dos gastos realizados com a prestação dos serviços de água e de esgoto, pressupôs que quando a tarifa média de esgoto é inferior à tarifa média praticada na prestação conjunta dos dois serviços, e essa é menor do que a despesa total com os dois serviços por metro cúbico faturado, há geração insuficiente de receitas dos serviços de esgotamento sanitário para a cobertura dos 
correspondentes custos. Foram analisados os dados referentes a 2.070 municípios, e observou-se que em 1.055 deles (correspondendo a aproximadamente 51\% do total), os resultados sugerem a insuficiência das tarifas cobradas dos usuários para fazer frente aos dispêndios associados tanto à prestação desses serviços, quanto à sua expansão e sua melhoria (ABAR, 20191).

A questão financeira é tema amplo e complexo, sendo preciso considerar a teoria econômica por trás do assunto. Segundo esta, os serviços de esgotamento sanitário não podem ser gestionados somente pela lógica de mercado, pois apresentam falhas que justificam a intervenção pública. Estas falhas de mercado podem ser classificadas, conforme Candido (2013), em: externalidades (positivas ou negativas), informação assimétrica, bens públicos e poder de mercados. Na tabela 2, estas falhas estão sistematizadas e exemplificadas.

Tabela 2: Possíveis falhas da teoria econômica nos serviços de esgoto.

\begin{tabular}{l|l}
\hline Falha & Descrição \\
\hline Externalidades & $\begin{array}{l}\text { Externalidade negativa: Ocorre devido a poluição difusa, apesar de gerar custos à } \\
\text { sociedade e à empresa prestadora, o poluidor não paga por isso. } \\
\text { Externalidade positiva: Surge devido ao impacto sobre a saúde da população, uma } \\
\text { vez que a oferta desse serviço eleva o bem-estar da população, ao mesmo tempo } \\
\text { em que reduz os custos sobre o sistema público de saúde. }\end{array}$ \\
\hline $\begin{array}{c}\text { Informação } \\
\text { assimétrica }\end{array}$ & $\begin{array}{l}\text { A empresa prestadora possui informações privilegiadas em relação ao seu serviço, } \\
\text { como por exemplo em relação aos principais ativos da empresa. Isto eleva a } \\
\text { complexidade da mensuração do capital investido pela empresa e, por conseguinte, } \\
\text { da proposição de um arcabouço regulatório mais preciso e justo para a cobrança } \\
\text { das tarifas. }\end{array}$ \\
\hline Bens públicos & $\begin{array}{l}\text { Neste caso a falha é gerada pelo fato dos bens públicos serem não exclusivos, ou } \\
\text { seja, não se pode excluir ninguém do consumo (ou uso) dele. Nesses casos, o Estado } \\
\text { passa a ofertar o bem ou serviço a partir de recursos orçamentários, os quais todos } \\
\text { pagam de forma indireta via impostos, taxas ou contribuições. }\end{array}$ \\
\hline Competição imperfeita & $\begin{array}{l}\text { Ocorre quando um produtor ou um grupo de produtores ou consumidores exerce } \\
\text { poder de mercado fixando o preço acima do custo marginal (monopólio e } \\
\text { oligopólio) ou abaixo do valor marginal (monopsônio e oligopsônio). }\end{array}$ \\
\hline
\end{tabular}

Fonte: Elaborado com base em Candido (2013).

Os serviços de esgotamento são considerados um monopólio natural, tendo em vista a condição das redes coletoras estabelecidas, as quais, devido seus custos, não seria economicamente viável o estabelecimento de redes coletoras 
rivais (ELNABOULSI, 1999). Ademais, considerando as outras falhas de mercado, os serviços possuem externalidades positivas e negativas; ocorrência de informação assimétrica entre as prestadoras e as demais instituições envolvidas com a governança; e também podem ser vistos como um bem público.

\section{REGULAÇÃO DO ESGOTAMENTO SANITÁRIO E CONTROLE SOCIAL}

Com a função de regular os serviços de esgotamento sanitário, surgem as agências reguladoras no texto da Lei $11.445 / 2007$. Essas entidades reguladoras atuarão na fiscalização e regulação dos serviços, devendo obedecer aos princípios de independência decisória, incluindo autonomia administrativa, orçamentária e financeira (BRASIL, 2007). A estrutura normativa a ser editada nas dimensões técnica, econômica e social pelas agências reguladoras estão indicadas na Figura 10, onde vê-se que se trata de vasto conteúdo e indispensável para garantir a adequada funcionalidade do setor.

Figura 10: Rol de normatização da atuação das Agências Reguladoras.

\begin{tabular}{|c|c|c|}
\hline \multicolumn{3}{|c|}{ Normas das Agências Reguladoras } \\
\hline \multicolumn{3}{|l|}{ Dimensão Técnica } \\
\hline \multicolumn{2}{|c|}{$\begin{array}{l}\text { Padróes e indicadores de qualidade } \\
\text { Requisitos operacionais e de manutenção } \\
\text { Metas progressivas de expansăo e de qualidade } \\
\text { Eficiência e eficácia dos serviços prestados } \\
\text { Medidas de contingências e de emergèncias }\end{array}$} & \multirow{5}{*}{ 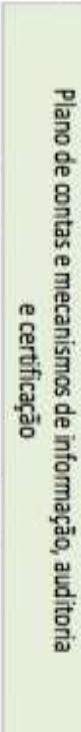 } \\
\hline Dimensão Econômica & क्वैधि & \\
\hline \multicolumn{2}{|c|}{$\begin{array}{l}\text { Regime, estrutura e niveis tarifários. Procedimentos } \\
\text { e prazos de sua fixação, reajuste e revisão } \\
\text { Mediçăo, faturamento e cobrança de serviços } \\
\text { Monitoramento dos custos } \\
\text { Rubsidios tarifários e não tarifários } \\
\text { contábil e do respectivo plano de contas }\end{array}$} & \\
\hline Dimensäo Social & 3987 & \\
\hline \multicolumn{2}{|c|}{$\begin{array}{c}\text { Padrōes de atendimento ao público e mecanismos } \\
\text { de participaçăo e informaçăo } \\
\checkmark \quad \text { Prazo para comunicar aos usuários as providências } \\
\text { adotadas relativas a reclamaçōes } \\
\quad \text { Padrōes de atendimento ao público e mecanismos } \\
\text { de participaçăo e informaçăo }\end{array}$} & \\
\hline
\end{tabular}

Fonte: Elaborado com base na Lei 11.445/2007 (BRASIL, 2007) e Decreto Federal 7.217/2010 (BRASIL, 2010). 
Os Titulares podem exercer a função de regulação diretamente ou delegála por meio de Convênio de Cooperação a outro ente da Federação ou Consórcio Público. Em qualquer um dos casos, deverá ser assegurada a publicidade dos relatórios, estudos e decisões que se refiram à regulação ou à fiscalização dos serviços, bem como dos direitos e deveres dos usuários e das prestadoras (BRASIL, 2007).

No Brasil, as Agências Reguladoras trabalham com dados obtidos e tratados quase que exclusivamente pelos prestadores dos serviços regulados, disponibilizados no SNIS, configurando-se em um problema para as Agências Reguladoras. Com a finalidade de resolver esta limitação, a ABAR propôs que as Agências poderiam ser as entidades responsáveis pela auditoria e certificação do SNIS. A metodologia desta proposta foi batizada pelo nome "Acertar" e conta com um Guia de Certificação do Projeto Acertar, atualmente em experimentação (ABAR, 20192).

Segundo von Sperling e von Sperling (2013), na atuação de regulação o uso de indicadores bem definidos torna-se necessário para estabelecer uma linguagem comum entre os diferentes atores, no que se refere ao desempenho e acompanhamento dos serviços. As principais instituições nacionais que lidam com indicadores para os serviços de esgotamento sanitário são: a Secretaria Nacional de Saneamento Básico - SNSB, por meio do SNIS; a Associação Brasileira de Agências Reguladoras - ABAR, através de seus estudos visando a proposição de um conjunto de indicadores para a regulação do saneamento; e a Associação Brasileira de Engenharia Sanitária - ABES, com a instituição do Prêmio Nacional de Qualidade em Saneamento - PNQS. No nível internacional, destacam-se: a International Water Association (IWA), a Entidade Reguladora dos Serviços de Águas e Resíduos de Portugal (ERSAR/IRAR), a Associación de Entes Reguladores de Agua Potable e Saneamiento de las Americas (ADERASA), o International Benchmarking Network for Water and Sanitation Utilities (IBNET), o Six-Cities Group da Escandinávia, a Water Services Association of Australia (WSAA), a American Water Works Association (AWWA) e a Office of Water Services (OFWAT).

Foram levantados entre estas instituições, 699 Indicadores de Desempenho (ID), sendo que 321 ID seriam específicos ao serviço de esgotamento sanitário, 216 ID ao serviço de abastecimento de água e 162 ID mistos. Neste último grupo estão a maioria dos ID relativos aos aspectos administrativos e financeiros 
das prestadoras de serviço. O SNIS, principal banco de dados brasileiro, possui 12 ID para esgoto, 35 ID para água e 37 ID mistos (VON SPERLING; VON SPERLING, 2013).

Dentro da gestão estabelecida pela PNSB, cabe ressaltar também a forma prevista para a participação social. Como ponderado por Jouravlel (2007), pelo fato de os usuários não terem a possibilidade de recorrer a outro prestador e a substituição da demanda ser sumamente limitada, ou até inexistente, a participação dos consumidores no processo regulatório é fundamental para se alcançar a regulação eficiente. A participação dos consumidores, argumenta o mesmo autor, deve ser institucionalizada e pode adotar diferentes modalidades, destacando-se (JOURAVLEL, 2007):

- Informação: consiste na geração e transmissão de informação sobre a prestação dos serviços. Pode ser por difusão, prestação de contas, capacitação ou educação cidadã relativo aos temas próprios do setor;

- Consulta: espaços ou fóruns cuja finalidade é promover o intercâmbio de informações entre o regulador, as empresas reguladas e os consumidores. Pode ser por meio de pesquisas e análises de opinião ou audiências públicas;

- $\quad$ Participação ativa: implica que os consumidores sejam não somente informados, mas também participem da tomada de decisão. Pode ser feita com base no envolvimento na gestão pública e a fiscalização cidadã.

Por sua vez, a Lei 11.445/2007 definiu o controle social como sendo o conjunto de mecanismos e procedimentos que garantem à sociedade informações, representações técnicas e participação nos processos de formulação de políticas, de planejamento e de avaliação relacionados com os serviços públicos de saneamento básico. O controle social dos serviços públicos de saneamento básico poderá incluir a participação de órgãos colegiados de caráter consultivo, estaduais, do Distrito Federal e municipais (BRASIL, 2007).

No entanto, a multivariedade de conselhos em um só município pode ser um fator complicador para a estruturação dos colegiados de saneamento básico. Não obstante os inúmeros conselhos serem necessários, nos pequenos municípios haverá dificuldades para organização de uma participação qualificada neste novo conselho. Há de se avaliar, inclusive, a possibilidade de fusão ou incorporação das 
discussões do saneamento básico por conselhos já estruturados como de meio ambiente ou de planejamento urbano (GALVÃO JÚNIOR; XIMENES, 2007).

\section{CONCLUSÃO}

O reconhecimento dos diferentes modais de esgotamento sanitário aplicáveis aos municípios brasileiros pelos atores envolvidos, torna-se imperativo para se alcançar a universalização desta dimensão do saneamento.

Destaca-se a necessidade do estabelecimento da governança pública através de mecanismos de estratégia, de controle e de liderança a serem postos em prática nos munícipios com vistas ao monitoramento, avaliação e direcionamento da prestação de serviço e de políticas públicas de esgotamento sanitário.

Instrumentos de governança precisam ser desenvolvidos e aplicados à realidade local dos municípios, pois a dimensão esgotamento sanitário em uma cidade é dinâmica e carece de constantes atualizações.

O novo marco legal, instituído pela Lei 14.026 de 15 de julho de 2020, precisa ser analisado visando identificar os pontos que foram alterados e os seus conteúdos. Destaca-se, no entanto, que se trata de um aprimoramento da gestão do saneamento, e não uma mudança drástica. Ou seja, os elementos do novo marco legal serão implementados gradualmente e com base em toda a história gerada pelo setor até o momento presente.

\section{REFERÊNCIAS}

ARAÚJO, Flávia Camargo de; BERTUSSI, Geovana Lorena. Saneamento básico no brasil: estrutura tarifária e regulação. Planejamento e Políticas Públicas: PPP, v. 1, n. 51, p.165-202, jul. 2018.

ASSOCIAÇÃO BRASILEIRA DAS AGÊNCIAS REGULADORAS - ABAR (Brasília).

Desafios e soluções para a universalização do esgotamento sanitário no Brasil. Brasília: ABAR, $2019^{1} .73 \mathrm{p}$.

ASSOCIAÇÃO BRASILEIRA DAS AGÊNCIAS REGULADORAS - ABAR (Brasília). Coletânea Regulação do Saneamento Básico 2019. Brasília: ABAR, 2019². 224 p. 
ASSOCIAÇÃO BRASILEIRA DE NORMAS TÉCNICAS. 14001: Sistemas da gestão ambiental. 3 ed. Rio de Janeiro: ABNT, 2015. 41 p.

BASTOS, Rafael Kopschitz Xavier. Oportunidades e desafios para os prestadores municipais de serviços de Saneamento Básico. In: BRASIL. Secretaria Nacional de Saneamento Ambiental. Ministério das Cidades (Ed.). Lei Nacional de Saneamento Básico: Perspectivas para as políticas e gestão dos serviços públicos - Prestação dos serviços públicos de saneamento básico. Brasília: Editora, 2009. p. 559-570. (Livro III).

BRASIL. Lei no 8666, de 21 de junho de 1993. Institui Normas Para Licitações e Contratos da Administração Pública. Brasília, DF, Disponível em: http://www.planalto.gov.br/ccivil_03/leis/L8666compilado.htm. Acesso em: 16 mar. 2020.

BRASIL. Lei no 8987, de 13 de fevereiro de 1995. Dispõe Sobre O Regime de Concessão e Permissão da Prestação de Serviços Públicos. Brasília, DF, Disponível em: http://www.planalto.gov.br/ccivil_03/leis/8987cons.htm. Acesso em: 16 mar. 2020.

BRASIL. Lei no 11107, de 6 de abril de 2005. Dispõe Sobre Normas Gerais de Contratação de Consórcios Públicos. Brasília, DF, Disponível em: http://www.planalto.gov.br/ccivil_03/_Ato2004-2006/2005/Lei/L11107.htm. Acesso em: 16 mar. 2020.

BRASIL. Lei no 11.445, de 5 de janeiro de 2007: Estabelece diretrizes nacionais para o saneamento básico. Brasília, DF, Disponível em:

http://www.planalto.gov.br/ccivil_03/_ato2007-

2010/2007/lei/L11445compilado.htm. Acesso em: 16 mar. 2020.

BRASIL. Decreto no 7217, de 21 de junho de 2010. Regulamenta A Lei no 11.445, de 5 de Janeiro de 2007, Que Estabelece Diretrizes Nacionais Para O Saneamento Básico. Brasília, DF, Disponível em:

http://www.planalto.gov.br/ccivil_03/_ato2007-2010/2010/decreto/d7217.htm. Acesso em: 16 mar. 2020.

BRASIL. Decreto no 9203, de 22 de novembro de 2017: Dispõe sobre a política de governança da administração pública federal direta, autárquica e fundacional. Brasília. Disponível em: http://www.planalto.gov.br/ccivil_03/_ato20152018/2017/decreto/D9203.htm. Acesso em: 16 mar. 2020.

BRASIL-ATLAS. Agência Nacional de águas. Ministério do Meio Ambiente. Atlas 
Esgotos: Despoluição de Bacias Hidrográficas. Brasília, 92 p. 2017.

BRASIL-IBGE. Instituto Brasileiro de Geografia e Estatística - IBGE. Pesquisa de Informações Básicas Municipais - MUNIC. 2017. Disponível em:

$<$ https://www.ibge.gov.br/estatisticas/sociais/saude/10586-pesquisa-deinformacoes-basicas-municipais.html?=\&t=o-que-e $>$. Acesso em: 12 jul. 2019.

CANDIDO, J. L. Falhas de mercado e regulação no saneamento básico. Revista Eletrônica Informe Econômico, 1(1), 85-89. 2013.

ELNABOULSI, J. C. What can we learn about water services management and privatization in france? Water Resources Planning And Management. p.1-25, jun. 1999.

GALVÃO JÚNIOR, Alceu de Castro; XIMENES, Marfisa Maria de Aguiar Ferreira. Desafios para os conselhos de saneamento básico. In: GALVÃO JÚNIOR, Alceu de Castro; XIMENES, Marfisa Maria de Aguiar Ferreira. Regulação: Controle social da prestação dos serviços de água e esgoto. Fortaleza: Pouchain Ramos, 2007. p. 6993.

GIKAS, Petros; TCHOBANOGLOUS, George. The role of satellite and decentralized strategies in water resources management. Journal of Environmental Management. p. 144-152. 20 fev. 2008.

HOPHMAYER-TOKICH, Sharon. Wastewater Management Strategy: centralized versus decentralized technologies for small communities. Cstm-reeks. [s.i], p. 127. jan. 2006. Disponível em:

$<$ https://research.utwente.nl/en/publications/wastewater-management-strategycentralized-v-decentralized-techno>. Acesso em: 30 maio 2019.

JOURAVLEL, A. Participação dos consumidores no processo Regulatório. In: GALVÃO JÚNIOR, Alceu de Castro; XIMENES, Marfisa Maria de Aguiar Ferreira. Regulação: Controle social da prestação dos serviços de água e esgoto. Fortaleza: Pouchain Ramos, 2007. p. 19-36.

MADEIRA, R. F. O setor de saneamento básico no Brasil e as implicações do marco regulatório para a universalização do acesso. Revista do BNDES, 33, p. 123-154. 2010.

MORAES, Luiz Roberto Santos. Política e Plano Municipal de Saneamento Básico: aportes conceituais e metodológicos. In: BRASIL. Secretaria Nacional de Saneamento Ambiental. Ministério das Cidades (Ed.). Lei Nacional de Saneamento 
Básico: Perspectivas para as políticas e gestão dos serviços públicos Instrumentos das políticas e da gestão dos serviços públicos de saneamento básico. Brasília: Editora, 2009. p. 33-53. (Livro I).

Secretaria Nacional de Saneamento - SNS. SNIS - Sistema Nacional de Informações sobre Saneamento. 2019. Disponível em: http://app4.mdr.gov.br/serieHistorica/. Acesso em: 16 mar. 2020.

VON SPERLING, Tiago Lages; VON SPERLING, Marcos. Proposição de um sistema de indicadores de desempenho para avaliação da qualidade dos serviços de esgotamento sanitário. Engenharia Sanitária e Ambiental, v. 18, n. 4, p.313-322, out. 2013. Trimestral.

ABRECON. Relatório Pesquisa Setorial. 2015. Disponível em: <https://abrecon.org.br/pesquisa_setorial/>. Acesso em: 10 abr. 2019.

BRASIL. Plano nacional de resíduos sólidos. 109 p. 2011. Disponível em:< http://www.mma.gov.br/estruturas/253/_publicacao/253_publicacao020220120 41757.pdf>. Acesso em: 11 abr. 2019.

BRASIL. Lei de Educação Ambiental no 9.795, de 27 de abril de 1999. Disponível em:< http://www.planalto.gov.br/ccivil_03/leis/l9795.htm >. Acesso em: 10 abr. 2019.

BRASIL. Lei no 12.305, de 2 de agosto de 2010. Institui a Política Nacional de Resíduos Sólidos, dispondo sobre seus princípios, objetivos e instrumentos. Disponível em: < http://www.planalto.gov.br/ccivil_03/_Ato20072010/2010/Lei/L12305.htm>. Acesso em:11 de abr. de 2019. 2010.

BRASIL. Ministério do Meio Ambiente- Secretaria de Recursos Hídricos e Ambiente Urbano. Elaboração do Plano Estadual de Resíduos Sólidos de Santa Catarina, v. 2, 402 p. 2017.

CAÇADOR. Aproveitamento e reciclagem de resíduos de construção civil e demolição no Município de Caçador- Lei no 3.478, de 14 de novembro de 2018. Disponível em: <https://leismunicipais.com.br/a/sc/c/cacador/leiordinaria/2018/348/3478/lei-ordinaria-n-3478-2018-dispoe-sobre-oaproveitamento-e-reciclagem-de-residuos-de-construcao-civil-e-demolicao-nomunicipio-de-cacador-e-da-outras-providencias>. Acesso em: 11 de abr. de 2019.

CONSELHO NACIONAL DO MEIO AMBIENTE. Resolução no 307, de 5 de julho de 2002. Publicada no DOU no 136, 17 de jul. de 2002, Seção 1, 95-96 p. 2002. 
Disponível em: <

http://www.mma.gov.br/estruturas/a3p/_arquivos/36_09102008030504.pdf>. Acesso em: 11 abr. 2019

LIMA, R.S; LIMA, R.R.R. Guia para Elaboração de Projeto de Gerenciamento de Resíduos da Construção Civil. p. 60, 2012.

NAGALLI, André. Gerenciamento de resíduos sólidos na construção civil. São Paulo: Oficina de Textos, 2014.

SENAI; SEBRAE. Gestão de resíduos na construção civil: redução, reutilização e reciclagem. 2018. Disponível em: < http://www.fieb.org.br/Adm/Conteudo/uploads/Livro-Gestao-deResiduos_id_177_xbc2901938cc24e5fb98ef2d11ba92fc3_2692013165855_.pdf >. Acesso em: 11 abr. 2019. 